\title{
The dose response effects of liquid and lyophilized Carnobacterium divergens AS7 bacteriocin on the nutrient retention and performance of broiler chickens
}

\author{
D. Józefiak ${ }^{1,4}$, A. Sip ${ }^{2}$, M. Rawski ${ }^{1}$, T. Steiner ${ }^{3}$ and A. Rutkowski ${ }^{1}$ \\ Poznań University of Life Sciences, \\ ${ }^{1}$ Department of Animal Nutrition and Feed Management \\ Wotyńska 33, 60-637 Poznań, Poland \\ ${ }^{2}$ Department of Biotechnology and Food Microbiology \\ Wojska Polskiego 48, 60-627 Poznań, Poland \\ ${ }^{3}$ BIOMIN Holding $\mathrm{GmbH}$ \\ Industriestrasse 21, 3130 Herzogenburg, Austria
}

(Received 20 May 2011; revised version 19 July 2011; accepted 9 August 2011)

\begin{abstract}
Efficacy of bacteriocin-divercin AS7 supplementation of broiler diets was evaluated. In two experiments one-day-old Ross 308 males were allocated randomly to six and eight dietary treatments, respectively, with 10 replicates (10 birds per replicate). In both experiments the birds were fed on diet non supplemented (negative control, NC) and supplemented with salinomycin (positive control, C). In Experiment 1, the effects of supplementation of the NC diet with 100, 200 or 800 units of liquid divercin, and in Experiment 2 with 100, 200 or 300 units of lyophilized divercin added in encapsulated or non-encapsulated form, were studied during starter and grower period. The response of birds in terms of feed intake, body weight gain (BWG) and feed efficiency (FE) depended on the growth period. In Experiment 1, supplementation of salinomycin or liquid divercin did not affect feed intake and BWG while FE was significantly improved by salinomycin. In Experiment 2, BWG was significantly improved by supplementation with salinomycin, all doses of non-encapsulated and the lowest dose of encapsulated divercin. In Experiment 1, the metabolizable energy content and fat digestibility tended to be greater in birds fed on diets supplemented with salinomycin and divercin than on NC diet, while in Experiment 2 were significantly greater on diet supplemented with salinomycin than on all other diets. It is suggested that divercin AS7 may improve performance of chickens but its efficacy depends on physical form.
\end{abstract}

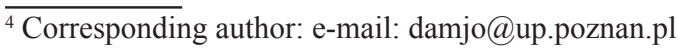


KEY WORDS: broiler chicken, salinomycin, divercin, encapsulation

\section{INTRODUCTION}

Approximately one third of all bacterial species excrete unique antimicrobial or bacteriostatic peptides called bacteriocins (Diez-Gonzalez, 2007; Leisner et al., 2007; Galvez et al., 2008). These substances present in the gastrointestinal systems of humans and animals play an important role in the colonization process of the microecosystem (Svetoch and Stern, 2010). Bacteriocins are heat and pH stable and are resistant to lipase and lysozyme; however, they are usually susceptible to digestion by proteolytic enzymes (Diez-Gonzalez, 2007; Galvez et al., 2008). Some features of these substances may be useful in the elimination of zoonotic bacteria from the poultry gastrointestinal tract (GIT), and potentially improve food chain safety and quality (Svetoch and Stern, 2010); however, to date, there are very limited data regarding their effects on broiler chicken performance.

The genus Carnobacterium contains nine species, two of them being most often isolated from cold and temperate environments (both terrestrial and aquatic) and from foods. They endure freezing/thawing and high pressure and are able to grow at low temperatures, in microaerophilic conditions (Leisner et al., 2007). The most frequently isolated Carnobacterium species are C. maltaromaticum and C. divergens, which are found in salmon, dairy products, beef, pork and lamb (Sip and Grajek, 2005).

Previous studies in our laboratories have shown that $C$. divergens AS7 bacteriocin (divercin AS7) may reduce bacterial colonization in vitro and in vivo, potentially improving broiler performance (Józefiak et al., 2010). In the experiments considering the influence of divercin on the broiler GIT microflora and nutrient retention, we used a constant liquid-form dosage of divercin AS7 that was estimated on the basis of in vitro experiments.

For practical applications in animal diets solid forms of divercin AS7 (lyophilized or encapsulated) are preferred due to their better handling and mixing properties. Furthermore, it is hypothesized that lyophilization or encapsulation may increase the stability of divercin AS7, hence potentially improve its in vivo efficacy in the GIT.

Until now there is no available information regarding the potential effectiveness of lyophilized and encapsulated divercin AS7 preparations. Therefore, the present experiments evaluate the impacts of different physical forms as well as dosages of this bacteriocin (liquid, lyophilized non-encapsulated or lyophilized encapsulated) on growth performance and nutrient utilization in broiler chickens. 


\section{MATERIAL AND METHODS}

\section{Material}

The divercin activity was quantified via 2-fold dilutions and is expressed in activity units (AU) per millilitre as previously described by Ennahar et al. (2001). The divercin AS7 liquid preparation was produced in Poznan Life Science University laboratories according to the technology described by Sip et al. (1999) and was provided in a liquid or lyophilized form. The lyophilization of the liquid divercin was performed in a lyophilizing cabinet (Christ 1825; Germany) for 5 days at a temperature of $-55^{\circ} \mathrm{C}$. Previously prepared lyophilized liquid divercin was mixed in aseptic conditions with a carrier (Arbocel, powdered cellulose, JRS, Germany) at a ratio of 3:1 (wt/wt). A hot melt coating of hydrated soyabean oil at a ratio of 1:1 (wt/wt) relative was applied to the lyophilized divercin AS7 in a fluidized bed device.

\section{Experimental design and animals}

Two feeding experiments differing in the applied dosage and physical form of the divercin AS7 were conducted. Broiler chickens were kept in floor pens (1.58 $\times 1.16 \mathrm{~m}$ ) over an experimental period of $35 \mathrm{~d}$. In the first experiment, a total of 500 one-day-old male ROSS 308 chicks were randomly distributed to 5 dietary treatments, 10 replicate pens per treatment and 10 birds per pen. In the second experiment, a total of 800 one-day-old male ROSS 308 chicks were distributed to 8 dietary treatments, 10 replicate pens per treatment and 10 birds per pen. The birds were exposed to the light and darkness according to the Council Directive 2007/43/EC.

\section{Diets and feeding programme}

In the first experiment, the positive control (C) diet (Table 1) was supplemened with the ionophore coccidiostat salinomycin $(60 \mathrm{mg} / \mathrm{kg})$, whereas the negative control (NC) did not contain any additives. The experimental groups were fed NC diet supplemented with 100,200 or $800 \mathrm{AU}$ of liquid divercin AS7/kg (diets D1, D2 and D8, respectively). The liquid divercin preparation was dissolved in sterile water, while in the $\mathrm{C}$ and $\mathrm{NC}$ treatment the same sterile water $(101 / \mathrm{t})$ was given as placebo. In all treatments water with or without divercin was added 'on top', in dosage $10 \mathrm{l} / \mathrm{t}$ of the complete feed.

Also in the second experiment, the positive control (C) diet was supplmented with salinomycin $(60 \mathrm{mg} / \mathrm{kg})$, whereas the negative control (NC) did not contain 
any additives. The experimental groups were fed NC diet supplemented with 100, 200 or $300 \mathrm{AU}$ of divercin encapsulated (diets ENC1, ENC2 and ENC3, respectively) or non-encapsulated (diets NENC1, NENC2 and NENC3, respectively). The encapsulated and non-encapsulated divercin AS7 was given at the expense of wheat in amounts accounting for mass of encapsulating substance.

The composition of the control diet is summarized in Table 1. In both experiments, from d 30 to 35 of the experiment, $0.2 \%$ titanium dioxide was included at the expense of wheat as an internal marker for digestibility analyses. The control diet was formulated to increase colonization of non-favourable GIT microbiota populations as Clostridiaceae, therefore viscous cereals and low quality fat not optimal for growth performance of the birds were used.

Table 1. Composition $\left(\mathrm{g} \cdot \mathrm{kg}^{-1}\right)$ and nutritional value of the control diet

\begin{tabular}{|c|c|}
\hline \multicolumn{2}{|l|}{$\begin{array}{l}\text { Item } \\
\text { Components }\end{array}$} \\
\hline $\begin{array}{l}\text { Components } \\
\text { triticale } \\
\text { wheat } \\
\text { soyabean meal } \\
\text { rapeseed meal } \\
\text { fish meal } \\
\text { tallow } \\
\text { monocalcium phosphate } \\
\text { limestone } \\
\text { DL-methionine } 20 \% \\
\text { L-lysine } 20 \% \\
\text { NaHCO } \\
\text { NaCl } \\
\text { mineral and vitamin premix }\end{array}$ & $\begin{array}{r}210.0 \\
467.0 \\
152.5 \\
42.0 \\
30.0 \\
43.7 \\
10.8 \\
2.9 \\
13.0 \\
15.0 \\
1.0 \\
2.1 \\
10.0\end{array}$ \\
\hline \multicolumn{2}{|l|}{ Calculated } \\
\hline $\begin{array}{l}\text { ME MJ } \cdot \mathrm{kg}^{-1} \\
\text { crude protein } \mathrm{g} \cdot \mathrm{kg}^{-1} \\
\mathrm{Lys} \mathrm{g} \cdot \mathrm{kg}^{-1} \\
\mathrm{Met}+\mathrm{Cys} \mathrm{g} \cdot \mathrm{kg}^{-1} \\
\mathrm{Ca} \mathrm{g} \cdot \mathrm{kg}^{-1} \\
\text { available } \mathrm{P} \mathrm{g} \cdot \mathrm{kg}^{-1}\end{array}$ & $\begin{array}{c}12.9 \\
205 \\
12.8 \\
9.0 \\
8.0 \\
4.4\end{array}$ \\
\hline
\end{tabular}

${ }^{1}$ provided per $\mathrm{kg}$ of diet: IU: vit. A 12,500 , vit. $\mathrm{D}_{3} 4,000$; $\mathrm{mg}$ : vit. $\mathrm{E} 50$, vit. $\mathrm{K} 3$, vit. $\mathrm{B}_{1} 2.2$, vit. $B_{2} 6.5$, vit. $B_{6} 3.8$, pantothenic acid 12.5 , choline chloride 400 , folic acid 1.5 , biotin 0.2 , vit. $B_{12}$ 0.025, BHT 10, Se 0.35, Fe 60, Zn 80, Mn 80, Cu 10, I 0.75; g: Ca 2.45

\section{Measurements and sample collection}

In both experiments, the feed intake and body weight of the chickens were measured on days 14 and 35. Mortality was checked throughout the entire 
experiment. To evaluate the apparent metabolizable energy $\left(\mathrm{AME}_{\mathrm{N}}\right)$ and total tract apparent nutrient digestibility, excreta were collected from every pen $(\mathrm{n}=10)$ over $3 \mathrm{~h}$ on day 35 , mixed and samples of approximately $100 \mathrm{~g}$ were immediately frozen, freeze-dried and ground before further analyses.

\section{Chemical analyses}

The feed samples were analysed in duplicate for crude protein, crude fat and crude fibre contents using AOAC (2005) methods 976.05, 920.39 and 2002.04, respectively. Samples were ground to pass through a $0.5 \mathrm{~mm}$ sieve. The titanium dioxide content of each sample was estimated according to Short et al. (1996) method in samples prepared according to Myers et al. (2004). The gross energy was determined using an adiabatic bomb calorimeter (KL-12Mn, Precyzja-Bit PPHU, Poland). The nitrogen content was analysed using a Kjel-Foss Automatic 16210 (A/S N. Foss Electric, Denmark) apparatus. The crude fat was determined using a Soxtex System HT-1043 Extraction Unit (Foss Tecator, Denmark). In excreta nitrogen, crude fat, gross energy and titanium dioxide were estimated.

\section{Calculations and statistical analysis}

The apparent digestibility coefficient of fat was calculated according to the following equation:

Fat digestibility $(\%)=\left\{1-\left[\left(\mathrm{TiO}_{2} \% \operatorname{diet} / \mathrm{TiO}_{2} \%\right.\right.\right.$ digesta/excreta $) \times($ fat $\%$ digesta/ excreta/fat $\%$ diet $)]\} \times 100$

The $\mathrm{AME}_{\mathrm{N}}$ content was calculated according to Hill and Anderson (1958) using titanium dioxide as indicator.

The study was set up as a completely randomized design, and data were tested using the GLM procedure of SAS (1990). Means were separated using Duncan's multiple range test. All statements of significance are based on $\mathrm{P}<0.05$.

\section{RESULTS}

In both experiments the birds were healthy and no mortality cases occurred. In the first experiment, the supplementation of salinomycin or liquid divercin AS7 preparation had no effect on the body weight gain (BWG) and feed intake throughout the starter, grower and entire experimental period (Table 2). Feed 
Table 2. The effect of dietary liquid divercin AS7 supplementation on the growth performance of broilers. Experiment 1

\begin{tabular}{|c|c|c|c|c|c|c|c|}
\hline \multirow[b]{2}{*}{ Item } & \multirow{2}{*}{$\begin{array}{l}\text { Positive control } \\
\text { salinomycin } \\
60 \mathrm{mg} / \mathrm{kg}\end{array}$} & \multirow{2}{*}{$\begin{array}{l}\text { Negative } \\
\text { control }\end{array}$} & \multicolumn{3}{|c|}{ Diet $^{1}$} & \multirow[b]{2}{*}{ SEM } & \multirow[b]{2}{*}{$\mathrm{P}$} \\
\hline & & & D1 & D2 & D8 & & \\
\hline \multicolumn{8}{|c|}{ Body weight gain, $\mathrm{kg}^{2}$} \\
\hline $1-14 d$ & 0.39 & 0.40 & 0.40 & 0.39 & 0.39 & 0.012 & 0.106 \\
\hline $15-35 d$ & 1.88 & 1.85 & 1.87 & 1.91 & 1.90 & 0.089 & 0.274 \\
\hline $1-35 d$ & 2.27 & 2.26 & 2.27 & 2.31 & 2.30 & 0.093 & 0.624 \\
\hline \multicolumn{8}{|c|}{ Feed intake, $\mathrm{kg}^{2}$} \\
\hline $1-14 d$ & 0.51 & 0.50 & 0.50 & 0.51 & 0.50 & 0.011 & 0.919 \\
\hline $15-35 d$ & 2.86 & 2.93 & 2.91 & 2.98 & 2.96 & 0.048 & 0.078 \\
\hline $1-35 d$ & 3.38 & 3.44 & 3.41 & 3.46 & 3.47 & 0.042 & 0.202 \\
\hline \multicolumn{8}{|c|}{ Feed efficiency, $\mathrm{kg}$ feed $/ \mathrm{kg}_{\mathrm{gain}}{ }^{2}$} \\
\hline $1-14 d$ & $1.31^{\mathrm{a}}$ & $1.26^{\mathrm{b}}$ & $1.25^{\mathrm{b}}$ & $1.28^{\mathrm{ab}}$ & $1.27^{\mathrm{b}}$ & 0.006 & 0.010 \\
\hline $15-35 d$ & $1.52^{\mathrm{b}}$ & $1.58^{\mathrm{a}}$ & $1.56^{\mathrm{a}}$ & $1.56^{\mathrm{a}}$ & $1.56^{\mathrm{a}}$ & 0.005 & 0.001 \\
\hline $1-35 d$ & $1.49^{\mathrm{b}}$ & $1.53^{\mathrm{a}}$ & $1.50^{\mathrm{ab}}$ & $1.51^{\mathrm{ab}}$ & $1.51^{\mathrm{ab}}$ & 0.004 & 0.006 \\
\hline
\end{tabular}

${ }_{1}^{1}$ diets D1, D2 and D3 contained 100, 200 and $800 \mathrm{AU}$ of liquid divercin $/ \mathrm{kg}$, respectively

${ }^{2}$ the means represent 10 pens of 10 chickens each; SEM - pooled standard error

efficiency (FE) in salinomycin supplemented group in the starter period was the worst while in the grower period was the best; in each period it did not differ among other groups. During the whole experiment FE was significantly improved by supplementation of negative control diet with salinomycin. Supplementation with divercin AS7 did not improve significantly FE either in starter or grower period, and in the whole experiment $\mathrm{FE}$ values for all divercin supplemented groups did not differ significantly from either positive or negative controls.

In the first experiment, salinomycin or divercin supplementation did not influence significantly $\mathrm{AME}_{\mathrm{N}}$ content of the diets or total fat digestibility (Table 3), however, a tendency to higher $\mathrm{AME}_{\mathrm{N}}$ values and fat digestibility was observed in the supplemented groups as compared with negative control.

Table 3. The effect of liquid divercin AS7 supplementation on the total tract metabolizable energy $\left(\mathrm{AME}_{\mathrm{N}}\right)$ value and total fat digestibility in broilers. Experiment 1

\begin{tabular}{lccccccc}
\hline Item & $\begin{array}{c}\text { Positive control } \\
\text { salinomycin } \\
60 \mathrm{mg} / \mathrm{kg}\end{array}$ & $\begin{array}{c}\text { Negative } \\
\text { control }\end{array}$ & $\mathrm{D} 1$ & $\mathrm{D} 2$ & $\mathrm{D} 8$ & SEM & $\mathrm{P}$ \\
$\begin{array}{l}\mathrm{AME}_{\mathrm{N}}, \mathrm{MJ} \\
\begin{array}{l}\text { Total fat } \\
\text { digestibility, } \%\end{array}\end{array}$ & 11.31 & 11.17 & 11.20 & 11.30 & 11.56 & 0.976 & 0.067 \\
\hline
\end{tabular}

${ }^{1,2}$ see Table 2

In the second experiment, lyophilized divercin preparations were added in non-encapsulated or encapsulated forms at three dietary levels (Tables 4 and 5). In the starter period, no effects of the dietary treatments on BWG were found. 


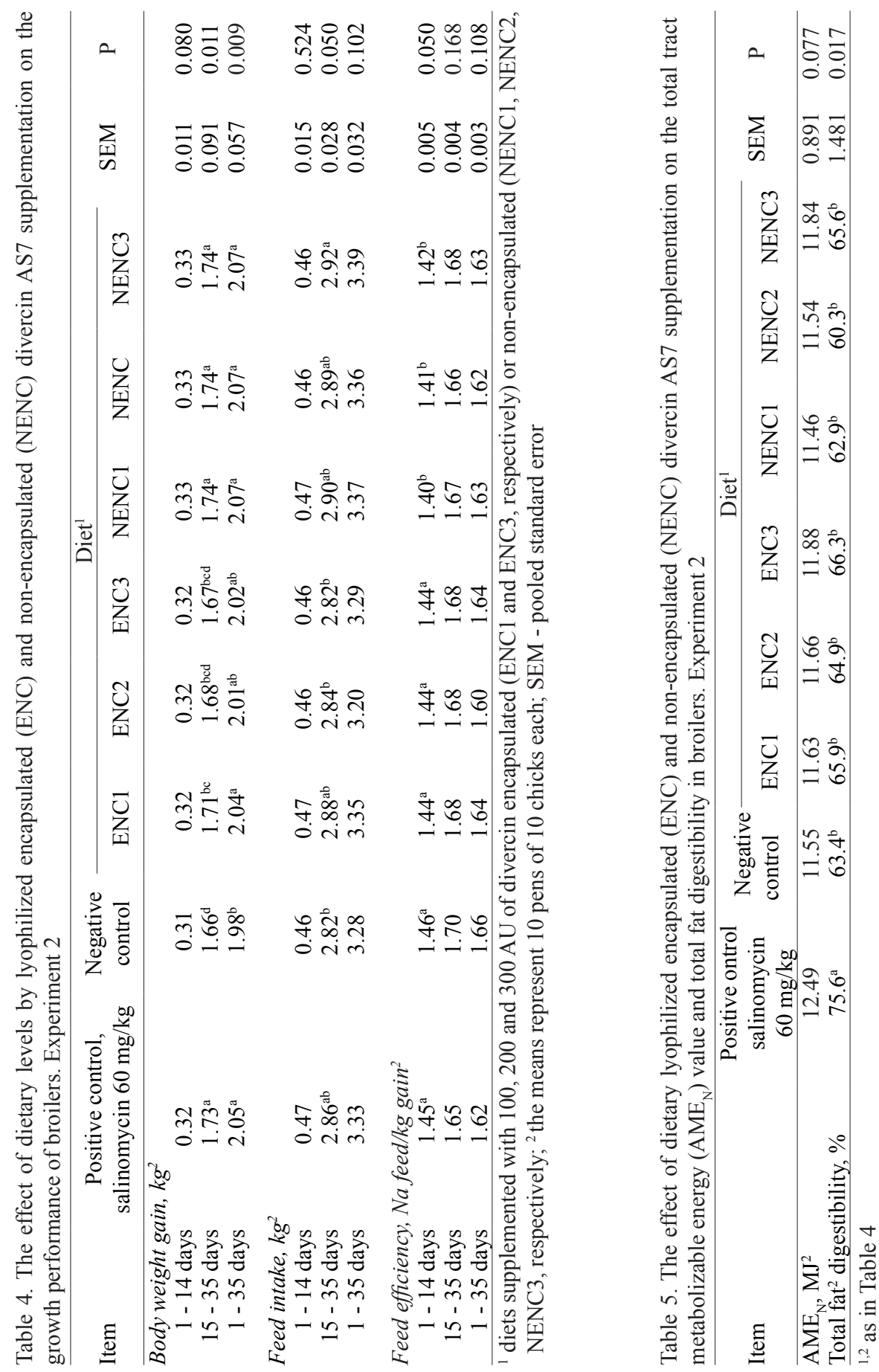


In the grower period, the BWG was the smallest on negative control diet and was increased by salinomycin, and by divercin in encapsulated form at the lowest level of supplementation (ENC1) and in non-encapsulated form at all dietary levels (NENC1, NENC2 and NENC3). Also in the entire growth period, BWG was the smallest on negative control diet and was increased by supplementation with salinomycin and divercin encapsulated fed at the lowest level and non-encapsulated fed at all three levels.

Feed intake was affected by dietary treatments only during the grower period. It was not influenced by salinomycin supplementation and tended to be greater in groups fed on diets supplemented with non-encapsulated than with encapsulated divercin but only intake of NENC3 diet was significantly greater than of negative control diet or diets supplemented with two higher doses of divercin (ENC2 and ENC3 diets).

The FE was affected only in the starter period and was better in groups fed on all diets supplemented with non-encapsulated divercin than on other diets, including group fed on diet supplemented with salinomycin (positive control).

The results of balance trial are summarized in Table 5. The apparent metabolizable energy content tended $(\mathrm{P}=0.077)$ to be the highest in the diet supplemented with salinomycin. The total fat digestibility was, on average, $10 \%$ units higher in group fed on salinomycin-supplemented diet $(\mathrm{P}=0.05)$ than on all other diets.

\section{DISCUSSION}

The observed growth-promoting effect of salinomycin is in agreement with the results of earlier studies on broiler chickens (Engberg et al., 2000), ruminants (Spears, 1990) and pigs (Moore et al., 1986). However in the first from current experiments, in the starter period, salinomycin supplementation impaired feed utilization. This interesting finding may suggest that in some cases, early salinomycin feeding can have negative effects on performance of broiler chickens, which may be due to changes in the colonization of the GIT by native microbiota.

It is well documented that in poultry, salinomycin not only targets Eimeria species but also certain Gram-positive bacteria in the GIT, where these substances reduce, e.g., the numbers of Clostridium perfringens (Bjerrum et al., 2005) and lactic acid bacteria, including the Lactobacillus species (Engberg et al., 2000). The observed improvement in bird growth and feed utilization by salinomycin can be explained by a limitation of microbial growth and activity, which involves direct competition with the host for nutrients and the microbial deconjugation of 
bile salts (Knarreborg et al., 2002), thus improving fat digestibility (Knarreborg et al., 2004). This idea agrees with the results of the present experiments, where salinomycin generally improved digestibility. The results of the second experiment demonstrate that the dietary supplementation of divercin AS7 may have beneficial effects on the growth of broiler chickens, since even at high dosages, i.e. at an activity of $800 \mathrm{AU} / \mathrm{ml}$, this bacteriocin does not impair body weight gain or feed conversion and tends to potentially increase $\mathrm{AME}_{\mathrm{N}}$ contents $(\mathrm{P}=0.0672$; Table 3); however, it also should be pointed out that increasing dietary divercin AS7 levels do not gradually improve the performance results. This observation agrees with our earlier studies which showed that high dosages had better in vitro bacteriostatic effects but did not improve nutrient digestibility in comparison with lower dosages (Józefiak et al., 2010). Moreover results of the present studies may suggest that in vivo divercin AS7 mode of action, is also correlated with GIT microflora composition and/or activity, giving beneficial effects for the host bird when the dietary factors disrupt GIT homeostasis.

In the present trials, for the first time, we have attempted to include encapsulated divercin AS7 in broiler chicken diets; however, the observed results are not very promising, as the application of $300 \mathrm{AU} / \mathrm{ml}$ in this form resulted in the lowest overall bird BWG as compared to the same dosage of the non-encapsulated formulation. On the basis of the present results it is difficult to explain this observation; however, in our previous experiments with liquid divercin, we have demonstrated that it is most active in the upper parts (i.e. the crop) of the broiler GIT. Therefore, it is suggested that the performance-promoting effects of divercin AS7 may partly be associated with a modification of the crop microflora, which is beneficial to the host bird. Therefore, the encapsulation of divercin may probably not offer any advantages.

So far, our knowledge on pure bacteriocins being used as feed additives in poultry diets is scarce; however, in recent years, more research has been focused on this topic, and several studies have demonstrated some positive effects. Additionally, several reports on bacteriocin applications seem to suggest that they may be beneficial not only as feed preservatives but also as animal performance enhancers. Some authors have discussed the positive effects of probiotics cultures when administered in feed in terms of their ability to produce bacteriocins (Nava et al., 2005). Therefore, in a study by Ogunbanwo et al. (2004), birds were challenged with $E$. coli $02: \mathrm{KH} 6$ and treated with a bacteriocin-producing strain of Lactobacillus plantarum F1 administered in drinking water. The performance of the birds was similar irrespective of the treatment; however, in the group of infected broilers, E. coli $02: \mathrm{KH} 6$ was reisolated in $60 \%$ of the birds, whereas, in the experimental group, the pathogen was present only in $12 \%$ of the birds. A recent study by Grilli et al. (2009) focused on the application of pediocin A, which 
is produced by Pediococcus pentosaceus FBB61. The in vivo performance trial demonstrated positive effects for this peptide, which improved the growth and feed utilization of broiler chickens that had been challenged with Clostridium perfringens. In a study by Cole et al. (2006), a significant reduction in Campylobacter jejuni in turkey poults was observed after the dietary addition of bacteriocin B602 from Paenibacillus polymyxa (NRRL B-30509) and bacteriocin OR7 from Lactobacillus salivarius (NRRL B-35014).

Unfortunately, most of the cited papers did not register the performance of broiler chickens, which makes comparison with present results difficult. Moreover, the mode of action of bacteriocins is highly specific and sometimes limited to very few strains of bacteria. However, it can be proposed that some bacteriocins, including divercin AS7, may improve BWG and feed utilization in broiler chickens to the same extent as ionophore coccidiostats.

\section{CONCLUSIONS}

On the basis of the present results is suggested that the physical form of the bacteriocins preparations can significantly influence their efficacy, as divercin after encapsulation in a fat matrix did not improve body weight gain to the same extent as non-encapsulated preparations. The diet composition, bird's health status as well as gastrointestinal tract (GIT) microflora colonization process probably can also influence bacteriocins efficacy. The poorer performance of the negative control group was improved by dietary divercin AS7 to the same extent as salinomycin. Thus it is suggested that more research should be conducted to estimate factors which affect bacteriocins mode of action in broiler chicken GIT.

\section{REFERENCES}

AOAC, 2005. Association of Official Analytical Chemists, Official Methods of Analysis. $18^{\text {th }}$ Edition. Arlington, VA

Bjerrum L., Pedersen A.B., Engberg R.M., 2005. The influence of whole wheat feeding on Salmonella infection and gut flora composition in broilers. Avian Dis. 49, 9-15

Cole K., Farnell M., Donoghue A. et al., 2006. Bacteriocins reduce Campylobacter colonization and alter gut morphology in turkey poults. Poultry Sci. 85, 1570-1575

Diez-Gonzalez F., 2007. Applications of bacteriocins in livestock. Curr. Issues Intest. Microbiol. 8, 15-24

Engberg R.M., Hedemann M.S., Leser T.D., Jensen B.B., 2000. Effect of zinc bacitracin and salinomycin on intestinal microflora and performance of broilers. Poultry Sci. 79 1311-1319

Ennahar S., Asou Y., Zendo T., Sonomoto K., Ishizaki A., 2001. Biochemical and genetic evidence for production of enterocins A and B by Enterococcus faecium WHE 81. Int. J. Food Microbiol. 70, 291-301 
Galvez A., Lopez R.L., Abriouel H., Valdivia E., Ben Omar N., 2008. Application of bacteriocins in the control of foodborne pathogenic and spoilage bacteria. Crit. Rev. Biotechnol. 28, 125-152

Grilli E., Messina M.R., Catelli E., Morlacchini M., Piva A., 2009. Pediocin A improves growth performance of broilers challenged with Clostridium perfringens. Poultry Sci. 88, 2152-2158

Hill F.W., Anderson D.L., 1958. Comparison of metabolizable energy and productive energy determinations with growing chicks. J. Nutr. 64, 587-603

Józefiak D., Sip A., Kaczmarek S., Rutkowski A., 2010. The effects of Carnobacterium divergens AS7 bacteriocin on gastrointestinal microflora in vitro and on nutrient retention in broiler chickens. J. Anim. Feed Sci. 19, 460-467

Knarreborg A., Engberg R.M., Jensen S.K., Jensen B.B., 2002. Quantitative determination of bile salt hydrolase activity in bacteria isolated from the small intestine of chickens. Appl. Environ. Microbiol. 68, 6425-6428

Knarreborg A., Lauridsen C., Engberg R.M., Jensen S.K., 2004. Dietary antibiotic growth promoters enhance the bioavailability of alpha-tocopheryl acetate in broilers by altering lipid absorption. J. Nutr. 134, 1487-1492

Leisner Jr. J., Laursen B.G., PrÈvost H., Drider D., Dalgaard P., 2007. Carnobacterium: positive and negative effects in the environment and in foods. FEMS Microbiol. Rev. 31, 592-613

Moore R.J., Kornegay E.T., Linderman D., 1986. Effect of salinomycin on nutrient absorption and retention by growing pigs fed corn-soybean meal diets with or without oat hulls or wheat bran. Can. J. Anim. Sci. 66, 257-265

Myers W.D., Ludden P.A., Nayigihugu V., Hess B.W., 2004. Technical Note: A procedure for the preparation and quantitative analysis of samples for titanium dioxide. J. Anim. Sci. 82, 179183

Nava G.M., Bielke L.R., Callaway T.R., Castaneda M.P., 2005. Probiotic alternatives to reduce gastrointestinal infections: the poultry experience. Anim. Health Res. Rev. 6, 105-118

Ogunbanwo S.T., Sanni A.I., Onilude A.A., 2004. Influence of bacteriocin in the control of Escherichia coli infection of broiler chickens in Nigeria. World J. Microbiol. Biotechnol. 20, 51-56

Short F.J., Gorton P., Wiseman J., Boorman K.N., 1996. Determination of titanium dioxide added as an inert marker in chicken digestibility studies. Anim. Feed Sci. Tech. 59, 215-221

Sip A., Grajek W., 2005. Antilisterial activity of divercin in ground beef. Folia Univ. Agric. 246, 255-266

Sip A., Grajek W., Boyaval P., 1999. Production of bacteriocin by Carnobacterium divergens in batch and continuous culture. Pol. J. Food Nutr. Sci. 8/49, 27-38

Spears J.W., 1990. Ionophores and nutrient digestion and absorption in ruminants. J. Nutr. 120, 632638

Svetoch E.A., Stern N.J., 2010. Bacteriocins to control Campylobacter spp. in poultry - A review. Poultry Sci. 89, 1763-1768 